\title{
Surgical removal of embolized atrial septal defect device from pulmonary artery
}

\author{
Suraj Wasudeo Nagre, MBBS, MS, MCh CVTS, DNB CVTS, Mumbai, India
}

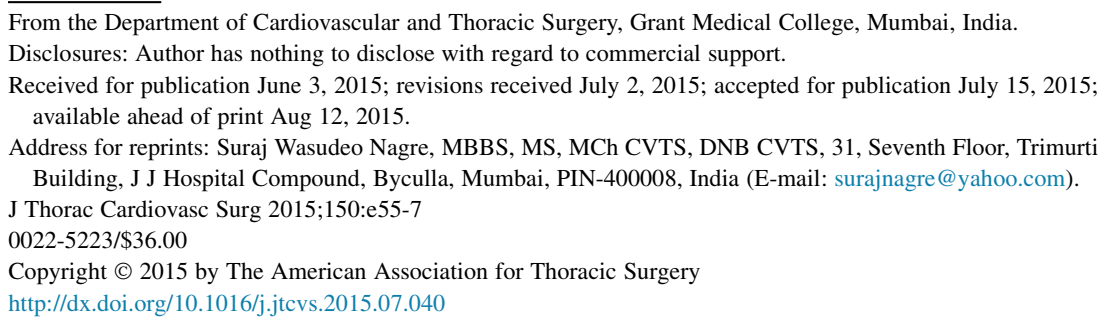

From the Department of Cardiovascular and Thoracic Surgery, Grant Medical College, Mumbai, India. Disclosures: Author has nothing to disclose with regard to commercial support.

Received for publication June 3, 2015; revisions received July 2, 2015; accepted for publication July 15, 2015; available ahead of print Aug 12, 2015.

Address for reprints: Suraj Wasudeo Nagre, MBBS, MS, MCh CVTS, DNB CVTS, 31, Seventh Floor, Trimurti Building, J J Hospital Compound, Byculla, Mumbai, PIN-400008, India (E-mail: surajnagre@yahoo.com). J Thorac Cardiovasc Surg 2015;150:e55-7

$0022-5223 / \$ 36.00$

Copyright (c) 2015 by The American Association for Thoracic Surgery

http://dx.doi.org/10.1016/j.jtcvs.2015.07.040

Atrial septal defect (ASD) is one of the most common congenital heart defects found in adults. Percutaneous device closure using the Amplatzer ASD occluder (AGA Medical Corp, Golden Valley, Minn) is widely used for the treatment of ASD and proven to be effective and safe as traditional surgical repair. However, procedure- or device-related complications can occur, which can be fatal. We report a rare case of subacute and silent embolization of an Amplatzer device to the pulmonary artery on the next day of successful percutaneous ASD closure.

\section{CLINICAL SUMMARY}

A 22-year-old man was admitted for symptoms of dyspnea that developed several months before admission. Transthoracic echocardiography (TTE) showed a secundum ASD measuring $28 \mathrm{~mm}$ anterior-posteriorly on apical 4-chamber view. Cardiac catheterization revealed pulmonary hypertension with a pulmonary artery systolic pressure of $42 \mathrm{~mm} \mathrm{Hg}$ and a large left to right shunt with a $\mathrm{Qp} / \mathrm{Q}$ s of 3.1. Transesophageal echocardiography was performed and showed a large secundum ASD measuring $30 \mathrm{~mm}$, with sufficient superior vena cava rim $(11 \mathrm{~mm})$ and inferior vena cava rim $(14 \mathrm{~mm})$, and relatively small atrioventricular rim $(5 \mathrm{~mm})$. Despite the relatively large size of the ASD with an insufficient aortic rim, percutaneous device closure with the Amplatzer device was planned because the patient refused surgical treatment. An oversized 32-mm Amplatzer ASD device was selected because of the insufficient aortic rim and deployed successfully after several failures of capturing the atrioventricular rim.

On the day after device closure, the patient was asymptomatic, and routine follow-up chest x-ray and TTE were performed. On chest x-ray, an Amplatzer device shadow was found on the main pulmonary trunk area (Figure 1, $A$ ), and TTE revealed the reappearance of the large ASD with the embolized Amplatzer device in the ostium of the right pulmonary artery (Figure $1, B$ ). The right ventricular systolic pressure was increased to $65 \mathrm{~mm} \mathrm{Hg}$, but the patient

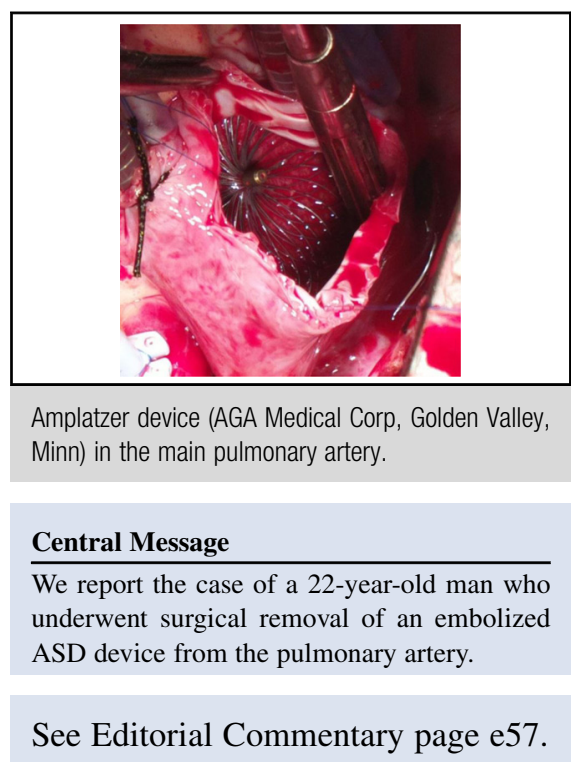

still remained asymptomatic and hemodynamically stable. We started an intravenous infusion of heparin and requested emergency surgery to remove the Amplatzer device and repair the ASD.

The operation was performed with a midline sternotomy. After cardiopulmonary bypass, the pulmonary artery was opened and the Amplatzer occluder was identified in the bifurcation site of the pulmonary artery trunk (Figure 2). The Amplatzer device was slowly removed, avoiding trauma to surrounding tissue. The ASD was closed using a pericardial patch, and the patient was discharged from the hospital on postoperative day 7 without other complications.

\section{DISCUSSION}

ASD is a prevalent congenital heart disease (3.78 per 10,000 live births). ${ }^{1}$ Surgical treatment is safe and effective, but the complications are related to thoracotomy, bleeding, arrhythmia, postpericardectomy syndrome, and residual defects. ${ }^{1}$ The ASD closure device was first described by Ring and colleagues in 1976. The devices used for closure are the CardioSEAL (NMT Medical Inc, Boston, Mass), Amplatzer septal occluder, and Angel Wings (Microvena Corp, White Bear Lake, Minn). ${ }^{2}$ The Amplatzer septal occluder is a device approved by the Food and Drug Administration for transcatheter closure of secundum ASDs and fenestrations after the Fontan operation. ${ }^{3,4}$ 

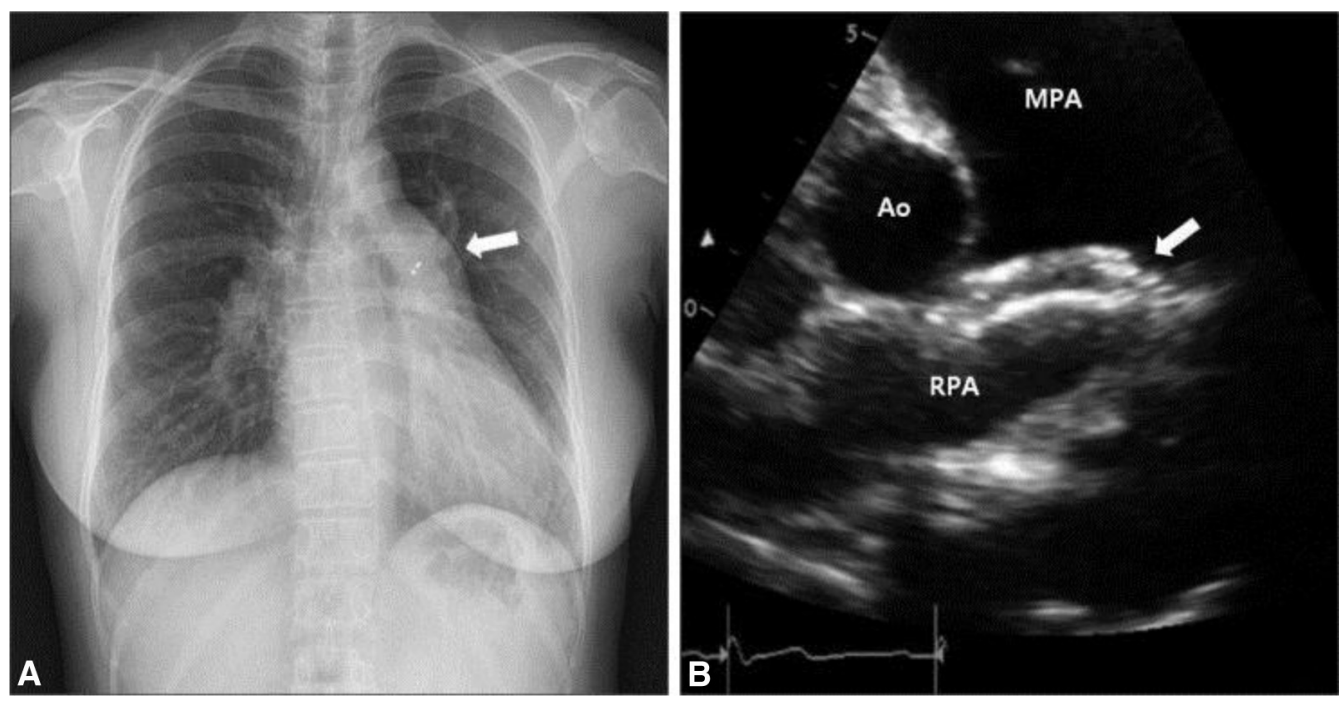

FIGURE 1. One day after the procedure, the embolized Amplatzer device (AGA Medical Corp, Golden Valley, Minn) was seen in the pulmonary artery (white arrow) on chest X-ray (A), which was lodged on the right pulmonary artery ostium (white arrow) on TTE (B). MPA, Main pulmonary artery; Ao, aorta; $R P A$, right pulmonary artery.

The complications of percutaneous ASD closure include air embolism, vascular trauma resulting from large sheathes, device embolization, clot embolization through the aortic valve, occlusion of pulmonary or systemic venous return, perforation of the atrial septum, aortic perforation, infective endocarditis, atrial arrhythmia, device malposition necessitating removal, delayed breakdown of device, and residual atrial. ${ }^{4}$ Among these, device embolization is a potential life-threatening complication requiring immediate removal via percutaneous or surgical intervention. Although the reported incidence is $0.01 \%$

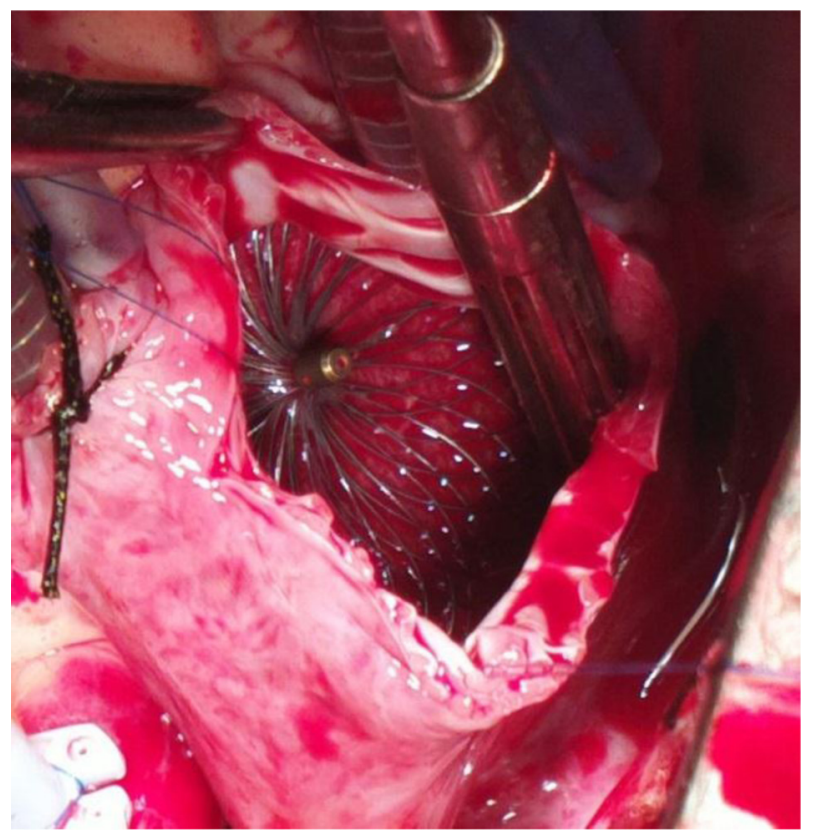

FIGURE 2. Amplatzer device in the main pulmonary artery. to $0.55 \%$, it would be higher in less-experienced operators. ${ }^{4-6}$ The common reasons for device embolization are undersized ASD device, a small left atrium to accommodate the device, inadequate or floppy rim, and operator-related technical issues. ${ }^{4}$ Immediate embolization occurs in the procedural field and is thought to be caused by malposition or incorrect device size. ${ }^{6}$ However, subacute embolization within several days of the procedure is thought to be associated in large part with aortic rim erosion or floppy septum.

In the present case, a nearly absent aortic rim and large defect size $(30 \mathrm{~mm})$ could be one reason for device migration. The combination of a small aortic rim and the floppy membranous nature of the counterpart rim (inferoposterior rim) increased the instability of the oversized Amplatzer device and may have led to migration and embolization of device in our patient. In approximately $50 \%$ of cases with Amplatzer occluder embolization, percutaneous retrieval is possible by using large sheaths, gooseneck snares, or endomyocardial biopsy forceps. However, surgical removal and repair of the ASD are preferable in cases with inappropriate ASD rims for the second procedure, as in the present case.

\section{CONCLUSIONS}

Strict criteria must be applied to select the device closure by comprehensive evaluation of the ASD. Careful monitoring for the possible delayed embolization is mandatory in the case of complicated ASD. Device embolization is an uncommon complication of Amplatzer ASD closure that can be managed surgically or by percutaneous extraction methods in centers with experienced surgeons. 


\section{References}

1. Jo SS, Han SJ, Jung MJ, Lee SJ, Seol KH, Kim GH, et al. Transcatheter closure of atrial septal defect using Amplatzer septal occluder. Korean Circ J. 2002;32: 17-24.

2. Chessa M, Carminati M, Butera G, Bini RM, Drago M, Rosti L, et al. Early and late complications associated with transcatheter occlusion of secundum atrial septal defect. J Am Coll Cardiol. 2002;39:1061-5.

3. King TD, Mills NL. Nonoperative closure of atrial septal defects. Surgery. 1974; $75: 383-8$.
4. Majunke N, Bialkowski J, Wilson N, Szkutnik M, Kusa J, Baranowski A, et al Closure of atrial septal defect with the Amplatzer septal occluder in adults. Am J Cardiol. 2009;103:550-4.

5. Du ZD, Hijazi ZM, Kleinman CS, Silverman NH, Larntz K, Amplatzer Investigators. Comparison between transcatheter and surgical closure of secundum atrial septal defect in children and adults: results of a multicenter nonrandomized trial. J Am Coll Cardiol. 2002;39:1836-44.

6. Levi DS, Moore JW. Embolization and retrieval of the Amplatzer septal occluder Catheter Cardiovasc Interv. 2004;61:543-7.

\title{
EDITORIAL COMMENTARY
}

\section{Do the benefits outweigh the risks? A review of the history of atrial septal defect repairs and device closures}

\author{
Meena Nathan, MD
}

From the Department of Cardiac Surgery, Boston Children's Hospital and Harvard Medical School, Boston, Mass. Disclosures: Author has nothing to disclose with regard to commercial support.

Received for publication Aug 12, 2015; accepted for publication Aug 13, 2015; available ahead of print Sept 2, 2015.

Address for reprints: Meena Nathan, MD, Department of Cardiac Surgery, Children's Hospital Boston and Harvard Medical School, 300 Longwood Ave, Bader 273, Boston, MA 02215 (E-mail: meena.nathan@ cardio.chboston.org).

J Thorac Cardiovasc Surg 2015;150:e57-8

$0022-5223 / \$ 36.00$

Copyright (C) 2015 by The American Association for Thoracic Surgery

http://dx.doi.org/10.1016/j.jtcvs.2015.08.049

The Centers for Disease Control and Prevention estimates that each year about 1966 babies are born with atrial septal defects (ASDs), representing about 5\% of the 40,000 children born with some form of congenital heart defect in the United States. ${ }^{1,2}$ The prevalence is 6.1 ASDs/10,000 live births, with a trend toward an increase in numbers in the last decade. ${ }^{3}$ Natural history studies indicate that if left unrepaired ASDs can result in progressive right ventricular volume overload, leading ultimately to right heart failure, elevated pulmonary vascular resistance, atrial arrhythmias, systemic thromboembolic events, and ultimately death. ${ }^{4}$

The first successful closure of an ASD was performed by F. John Lewis in 1952 with inflow occlusion under hypothermia. ${ }^{5}$ Since then, the continuing innovations in surgical and cardiopulmonary bypass techniques and cardiac anesthesia have decreased mortality risk from greater than $50 \%$ in the early era to less than $0.1 \%$ in the current era, ${ }^{6}$ with a significant reduction in length of stay as minimally invasive techniques have come into vogue. Surgical ASD closure remains the only therapeutic option for primum ASD and sinus venosus ASD. Surgical ASD closure does carry with it the very small risk of cerebrovascular event related to air embolism during CPB and also is associated with such minor morbidities as

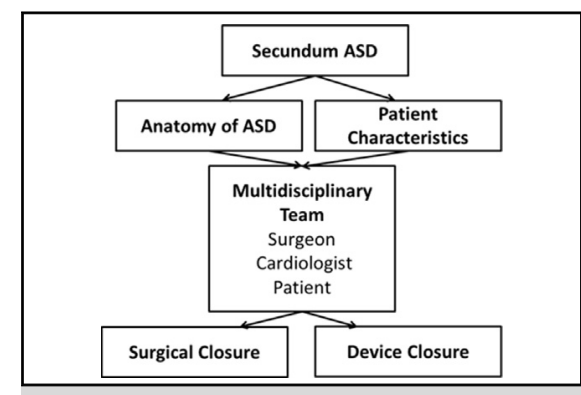

Approach to decision making for management of secundum atrial septal defects.

\section{Central Message}

Ideal management of ASD requires a multidisciplinary approach that includes ASD anatomy and patient characteristics and wishes.

See Article page e55.

postpericardiotomy syndrome, postoperative bleeding, rare reoperations for recurrence, and infection.

In the past decade, there has been a trend toward transcatheter closure of ASDs, particularly secundum ASDs, with appropriate anatomy. Moore and colleagues ${ }^{8}$ have provided an excellent review on transcatheter device closure of ASDs, with particular emphasis on safety. The first ASD device closure was performed by King and Mills in 1974 with a Dacron polyester fabric-covered steel umbrella. Since then, these devices have gone through several iterations of shape and material. ${ }^{8}$ The devices most commonly used in the current era include the Amplatzer Septal Occluder (ASO; nickel and titanium alloy 